\title{
(6) OPEN ACCESS \\ Is regular drinking in later life an indicator of good health? Evidence from the English Longitudinal Study of Ageing
}

\author{
Clare Holdsworth, ${ }^{1}$ Marina Mendonça, ${ }^{1}$ Hynek Pikhart, ${ }^{2}$ Martin Frisher, ${ }^{3}$ \\ Cesar de Oliveira, ${ }^{2}$ Nicola Shelton ${ }^{2}$
}

\begin{abstract}
- Additional material is published online only. To view please visit the journal online (http://dx.doi.org/10.1136/jech2015-206949)

${ }^{1}$ School of Physical and Geographical Sciences, Keele University, Keele, UK

${ }^{2}$ Department of Epidemiology \& Public Health, University College London, London, UK ${ }^{3}$ School of Pharmacy, Keele University, Keele, UK
\end{abstract}

\section{Correspondence to} Professor Clare Holdsworth, School of Physical and Geographical Sciences, Keele University, William Smith Building, Keele ST5 5BG UK: c.m.holdsworth@keele.ac.uk

Received 9 November 2015 Revised 21 December 2015 Accepted 1 January 2016

Published Online First 21 January 2016

\section{CrossMark}

To cite: Holdsworth $\mathrm{C}_{\text {, }}$ Mendonça M, Pikhart $\mathrm{H}_{\text {, }}$ et al. J Epidemiol Community Health 2016;70:764-770

\section{ABSTRACT}

Background Older people who drink have been shown to have better health than those who do not. This might suggest that moderate drinking is beneficial for health, or, as considered here, that older people modify their drinking as their health deteriorates. The relationship between how often older adults drink and their health is considered for two heath states: self-rated health (SRH) and depressive symptoms.

Methods Data were analysed from the English Longitudinal Study of Ageing (ELSA), a prospective cohort study of older adults, using multilevel ordered logit analysis. The analysis involved 4741 participants present at wave 0, (1998/1999 and 2001), wave 4 (2008/2009) and wave 5 (2010/2011). The outcome measure was frequency of drinking in last year recorded at all three time points.

Results Older adults with fair/poor SRH at the onset of the study drank less frequently compared with adults with good SRH $(p<0.05)$. Drinking frequency declined over time for all health statuses, though respondents with both continual fair/poor SRH and declining SRH experienced a sharper reduction in the frequency of their drinking over time compared with older adults who remained in good SRH or whose health improved. The findings were similar for depression, though the association between depressive symptoms and drinking frequency at the baseline was not significant after adjusting for confounding variables.

Conclusions The frequency of older adults' drinking responds to changes in health status and drinking frequency in later life may be an indicator, rather than a cause, of health status.

\section{INTRODUCTION}

The relationship between drinking and health in later life is an important component of older age mortality and morbidity. In the UK, for example, older adults consume less than younger age groups, though drink more regularly. ${ }^{12}$ Statistics for mortality and hospital admissions demonstrate that health problems associated with excessive drinking are most acute in later life. Alcohol-related mortality is higher among older age groups and is increasing among the elderly while stabilising and declining at younger ages. ${ }^{3}$ Between 2002 and 2010 in England and Wales, the number of alcoholrelated admissions into hospital for men aged 65 increased by $175 \%$ and for women by $145 \%{ }^{4}$

However, the causal relationship between health and drinking is complex. There is a well-established J-shaped relationship between health and alcohol, as moderate drinkers have better health outcomes than both abstainers and heavy drinkers, though the explanation for this association in disputed. ${ }^{5}$ In contrast to those who abstain, older moderate drinkers (as measured by quantity of consumption) have better cognition, ${ }^{6-8}$ improved well-being, ${ }^{6}$ and less substantial functional health decline or limitations. ${ }^{9} 10$ Moderate drinkers also report fewer depressive symptoms, medication use and acute health events, ${ }^{11}$ and overall have lower mortality risks, ${ }^{9}$ including cardiovascular disease. ${ }^{12}$ At the other end of the drinking spectrum, heavy drinkers are more likely to suffer mild cognitive impairment, ${ }^{7}$ greater incidence of pain, ${ }^{13}$ higher mortality, ${ }^{14}$ increased risk of injury ${ }^{15}$ and, for men only, greater risk of depression. ${ }^{16}$

The possibility that there might be health benefits associated with moderate drinking has generated considerable interest and discussion. Yet the extent to which these findings can confirm the causality between alcohol consumption and health remains contested. ${ }^{5}{ }^{17-20}$ The relationship between abstinence and poor health can be explained partly by the 'sick quitter effect', so drinkers are selected for good health. ${ }^{21}$ Longitudinal studies have sought to control for this bias by distinguishing lifetime abstainers from former drinkers, as the latter group are potentially sick quitters. ${ }^{5}{ }^{22} 23$ However, this distinction may not be sufficient to confirm causality. Studies need to consider that lifetime nondrinkers may also be selected for poor health ${ }^{24}$ and healthy drinkers suffer mortality before old age. ${ }^{25}$

We sought to analyse how changes in health statuses (as measured by SRH and depressive symptoms) in later life were associated with changes in drinking frequency over a 10 -year period. The analysis considered whether the frequency of drinking in later life is an indicator of health status and the possibility that older adults, who continue to drink frequently in later life, do so because they are healthy. Using longitudinal data on both drinking frequency and health status, the analysis considers how health is associated with drinking frequency at the onset of the period of observation and whether older adults moderate how often they drink as their health changes over time. This analysis was restricted to drinking frequency for two reasons. First, research on alcohol consumption has focused on the relationship between quantity of alcohol consumed and health outcomes. It has been shown that older adults drink more often though overall consumption declines with age. ${ }^{2} 32627$ However, it 
remains unclear how changing health status in later life affects the regularity of drinking. Second, we are not seeking to identify a dose response of alcohol consumption in response to changes in health, but consider how older adults' drinking behaviours, as measured by frequency, change as their health deteriorates or improves.

The analysis considered two health outcomes: self-rated health (SRH) and depression. SRH was used as an indicator of health, as it is a strong predictor of mortality. ${ }^{28}$ The relationship between SRH and drinking confirms that good health is associated with consumption rather than abstinence. ${ }^{29}{ }^{30}$ Depression is associated with increased risk of problem drinking in later life, ${ }^{1631}$ and it has been shown that moderate consumption is associated with better mental health. ${ }^{6}$ By comparing the relationship between the two health variables and drinking frequency, we can demonstrate if different health statuses have similar influences on drinking. Variables to capture sociodemographic status and life style behaviours (wealth, employment, marital status, education, body mass index (BMI) and smoking) are included in the analysis to examine the extent to which the relationship between health outcomes and frequency of drinking can be explained by confounding variables.

\section{DATA}

Data obtained from waves 0,4 and 5 of the English Longitudinal Study of Ageing (ELSA) were used for this analysis. $^{32}$ The derivation of the sample for the analysis is outlined in figure 1. Participants in wave 0 of ELSA were recruited from the Health Survey for England (HSE) in 1998, 1999 and 2001. The first wave of ELSA (wave 1, sample size 11205 ) was carried out in $2002 / 2003$. The sample has been interviewed every 2 years, with wave 4 recruited in 2008/2009 and wave 5 in 2010/2011. Though ELSA has included questions on alcohol consumption in all waves, the precise questions asked have varied. Our analysis is restricted to waves 0,4 and 5 where there was comparability in questions on alcohol consumption. The analysis was restricted to respondents in all three waves (4741 cases), and we excluded respondents who have either left the study over time, or were recruited to refresh it over the 10 -year period.

\section{Measures}

Outcome variable: Frequency of alcohol consumption. Waves 0 , 4 and 5 of ELSA included a measure about the frequency of any alcohol consumed in the past 12 months. Responses varied from 1 'almost every day' to 8 'not at all in the past 12 months'. Non-drinkers in ELSA did not answer this question, and we have combined this group with participants who did not drink at all in the past 12 months to form the category 'does not drink'. The distribution of this variable at the three waves is given in table 1. Just over one in five older adults reported drinking every day at wave 0 , though by wave 5 , non-drinkers were the modal group.

\section{Covariates}

Self-rated health: Participants were asked to rate their health on a five-point scale. The responses were converted into a two level variable-good and fair/poor. We developed a variable to measure transitions in health which distinguished between individuals who reported stable SRH between waves 0 and 5, that is, had constant good or fair/poor SRH in both waves, and individuals whose health changed over the 10-year period, that is, their health either improved (fair/poor to good) or deteriorated (good to fair/poor) between waves 0 and 5 .
Depressive symptoms: Depressive symptoms were measured by a short version of the Centre for Epidemiological Studies-Depression (CES-D) scale containing eight dichotomous items about depressive symptoms experienced in the last week. ${ }^{33}$ We derived a CES-D score by summing responses to all eight dichotomous questions. These summary scores were dichotomised using a cut point of four or higher $(\geq 4)$, which is equivalent to the conventional cut point of 16 or higher on the full 20-item CES-D representing being 'at risk' of depression. ${ }^{33}$ This variable distinguishes between individuals who were in the same 'at risk' of depression between waves 0 and 5 and individuals who either became 'at risk' or stopped being 'at risk' over the 10 -year time period between waves 0 and 5 .

Other covariates (see online supplementary appendix 1) measured at wave 0 included gender, age, marital status, education, employment status, BMI and smoking behaviour. Additional information on net non-pension household wealth for each individual was obtained from wave 1 of the study. This is a summary measure of the value of financial, physical and housing wealth owned by the household minus any debt. Wealth was included in the model as a relative measure divided into quintiles. In the final models, all variables were fitted including missing cases though these are not reported in the Results section.

\section{Data analysis}

To address the proposed aim for this study, we used a multilevel modelling approach and models were run separately for each health variable as a covariate to compare how changes in these two health statuses were associated with drinking frequency over time. Since drinking frequency over the previous year is a categorical ordered variable, rather than a linear variable, we performed a multilevel ordered logit analysis with STATA V.13, using command meologit. The longitudinal ELSA data can be viewed as having a two-level hierarchical structure as follows. Level 1 described within-person change; that is, how respondents' frequency of drinking changed over time. Level 2 described between-person differences in drinking frequency over time. Analysis at this level provides information about the individuals' initial drinking frequency (intercept) and trajectory during the study period (slope). In this analysis, we investigated how the rate of change over time in frequency varied according to changes in two health statuses (SRH and depression). Data on the frequency of drinking were available at three time points (waves 0,4 and 5), and the measure of time in the analysis was wave which was fitted as a categorical variable with three categories. Level 2 analysis was included by fitting an interaction term between health status and wave.

\section{RESULTS}

Tables 2 and 3 summarise the relationship between the transition variables for SRH and depressive symptoms and the frequency of drinking at wave 0 . This cross-sectional analysis demonstrated a clear relationship between good health/no depression and frequent drinking. One-quarter of all adults who reported good health drank every day at wave 0 , compared with $14.8 \%$ of those with fair/poor health. Moreover, in wave 0 , adults whose health/depression symptoms subsequently deteriorated were more likely to drink infrequently or not drink at all. Among older adults whose SRH deteriorated, $18.5 \%$ drank a few times a year or not at all at wave 0 compared with $10.8 \%$ of those who remained in good health at all subsequent waves; for depression, the equivalent percentages were $18.6 \%$ and $13.4 \%$. 
Figure 1 Flow chart illustrating selection of longitudinal sample (ELSA, English Longitudinal Study of Ageing; HSE, Health Survey for England).

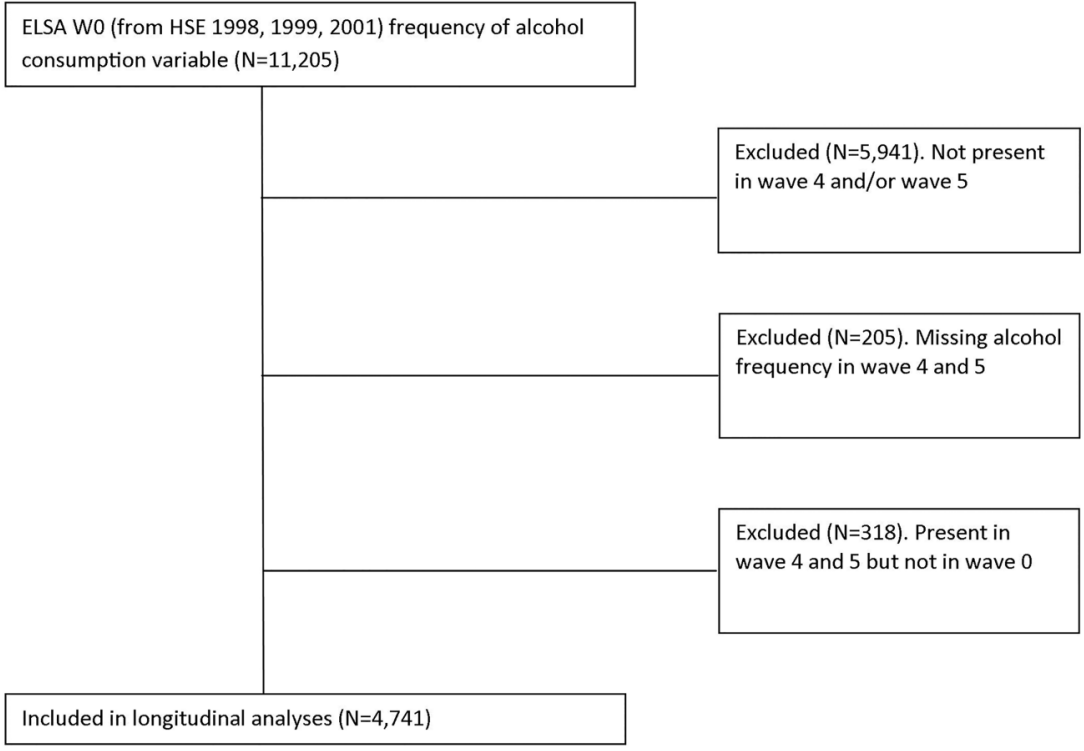

Analysis of key variables has shown that attrition between waves 0 and 4/5 was higher among non-drinkers rather than drinkers. ${ }^{34}$ This was confirmed using logistic regression analysis of being present in wave 5 for wave 0 respondents. This analysis found that non-drinkers in wave 0 were less likely to be present in wave 5 compared with all other drinking frequencies. To consider the possible impact of attrition on the findings, the longitudinal models were carried out for younger cohort of older adults (age less than 70 in wave 0 ) who were less likely to leave the study over the 10-year period. This analysis of this restricted age cohort gave the same results as the full models which are reported below, suggesting that attrition did not affect the results.

The results of the longitudinal analysis are given in table 4 (for analysis including transitions in SRH) and table 5 (for analysis including transitions in depressive symptoms). We report the ordered log-odds regression coefficients for two models for each health variable: model $1 \mathrm{a}$ included transitions in SRH, gender, age at wave 0 and transition in SRH $\times$ wave interaction and model $1 \mathrm{~b}$ included these variables and all covariates measured at wave 0: employment status, education, marital status, smoking, BMI and wealth (measured at wave 1). Models $2 \mathrm{a}$ and $2 \mathrm{~b}$ replicated this analysis substituting transitions in depressive symptoms for SRH. Negative coefficients indicate that

Table 1 Frequency of drinking in last year by wave $(\mathrm{N}=4741)$

\begin{tabular}{lccc}
\hline Frequency of drinking & $\begin{array}{l}\text { Wave } \mathbf{0} \\
\text { Per cent }\end{array}$ & $\begin{array}{l}\text { Wave } \mathbf{4} \\
\text { Per cent }\end{array}$ & $\begin{array}{c}\text { Wave 5 } \\
\text { Per cent }\end{array}$ \\
\hline Does not drink & 8.7 & 21.3 & 22.4 \\
Once/twice a year & 7.1 & 7.9 & 9.4 \\
Once every couple of months & 5.6 & 6.3 & 6.2 \\
1-2 times a month & 11.7 & 9.8 & 10.5 \\
1-2 days a week & 24.9 & 21.4 & 20.8 \\
3-4 days a week & 15.2 & 10.5 & 10.5 \\
5-6 days a week & 5.0 & 5.7 & 4.5 \\
Almost every day & 21.9 & 15.3 & 15.6 \\
\hline
\end{tabular}

Base: English Longitudinal Study of Ageing (ELSA) members in waves 0, 4 and 5. There are a small number of respondents with missing information in wave $4(2.24 \%)$ and wave $5(1.88 \%)$. individuals with a particular characteristic had a higher chance of drinking less frequently compared with those in the reference category; positive coefficients indicate a higher chance of more frequent drinking.

Age and gender were negative and significant in all models, illustrating that older women drank less frequently than men and for both genders drinking frequency declined with age. The results for the different health variables were broadly similar, though there was a small difference between the unadjusted and adjusted models for depressive symptoms compared with SRH. Taking SRH first (models $1 \mathrm{a}$ and $1 \mathrm{~b}$ ), there was a strong association between SRH and the frequency of drinking. In the unadjusted model (1a), respondents with continual fair/poor, improving and deteriorating SRH had a higher chance of drinking less frequently compared with respondents in continual good health at all waves. The regression coefficients were greatest for the category continual fair/poor SRH, demonstrating that this group were more likely to drink less frequently than all other health categories at all waves. The coefficients for each health status at waves 4 and 5 illustrate that all adults, regardless of health status, were more likely to drink less frequently in later waves. These coefficients were greater for older adults in continual fair/poor or declining SRH, compared with those with continual good or improving health. Thus, the differential in drinking frequency by SRH observed at wave 0 increased over time. The coefficients for the non-adjusted and adjusted models were broadly similar; though including confounding variables in model $1 \mathrm{~b}$ reduced the differences in drinking frequency by health status at each wave, but enhanced the difference within each health status over time. The differential at wave 0 between older adults in continual good health and those whose health subsequently declined was no longer significant in model $1 \mathrm{~b}$.

The findings for depressive symptoms were broadly similar to SRH in the unadjusted model (2a). However, after covariates were included in the adjusted model (2b), the association between drinking frequency and depressive symptoms at wave 0 was not significant. Yet in subsequent waves, and in both unadjusted and adjusted models, older adults with continual depressive symptoms were more likely to drink less frequently at all waves. The decline over time for this group was greater than other categories of depressive symptoms. As with SRH older adults whose depressive symptoms improved over time 
Table 2 Cross-tabulation of frequency of drinking at wave 0 by transitions in self-rated health between waves 0 and 5

\begin{tabular}{|c|c|c|c|c|}
\hline \multirow[b]{3}{*}{ Frequency of drinking wave 0} & \multicolumn{4}{|c|}{ Self-rated health: transitions between waves 0 and 5} \\
\hline & \multicolumn{2}{|l|}{ Good health wave 0} & \multicolumn{2}{|l|}{ Fair/poor health wave 0} \\
\hline & $\begin{array}{l}\text { Continual good health } \\
n=2753 \\
\text { Per cent }\end{array}$ & $\begin{array}{l}\text { Health deteriorates } n=748 \\
\text { Per cent }\end{array}$ & $\begin{array}{l}\text { Health remains fair/poor } \\
n=596 \\
\text { Per cent }\end{array}$ & $\begin{array}{l}\text { Health improves } n=497 \\
\text { Per cent }\end{array}$ \\
\hline Does not drink & 5.4 & 9.1 & 16.8 & 13.9 \\
\hline Once/twice a year & 5.4 & 9.4 & 11.0 & 9.5 \\
\hline Once every couple of months & 5.4 & 6.7 & 6.6 & 6.4 \\
\hline 1-2 times a month & 11.7 & 10.7 & 11.9 & 13.3 \\
\hline $1-2$ days a week & 26.1 & 25.5 & 22.1 & 22.3 \\
\hline 3-4 days a week & 16.4 & 12.1 & 13.1 & 13.7 \\
\hline 5-6 days a week & 5.8 & 4.5 & 3.7 & 3.6 \\
\hline Almost every day & 24.6 & 22.0 & 14.8 & 17.3 \\
\hline
\end{tabular}

experienced a smaller decline in frequency compared with those with continual depressive symptoms and who became at risk of depression. Older adults with no risk of depression at all waves drank more often than all other categories and experienced the smallest decline in frequency between the waves.

\section{DISCUSSION}

Older adults with fair/poor SRH throughout the period of observation and those whose SRH deteriorated over the 10 years experienced a faster decline in the frequency of drinking compared with older adults with constant good SRH. Respondents whose SRH improved over the period drank less frequently over time, but this reduction was less compared with older adults whose SRH deteriorated or remained poor/fair. Thus, the selection effect of SRH on drinking frequency is shown to be ongoing and older adults with continual good or improving SRH reported more consistent drinking over time. ${ }^{30}$ The relationship between depressive symptoms and drinking frequency is broadly similar to SRH. The relationship between drinking and both health variables is modified in the adjusted models, which demonstrates that socioeconomic characteristics explain some of observed relationship between health and drinking frequency, particularly for depressive symptoms.

The strength of this study is that it considers the dynamic relationship between two health statuses, SRH and depressive symptoms, and drinking frequency over time. The analysis demonstrates that alterations in drinking frequency in later life were associated with health conditions and how these changed over time. We confirm earlier studies that found declining frequency of drinking in later life associated with health, gender, wealth, education and age. ${ }^{29} 30$ 35-37 The finding that drinking frequency declines over time among older adults contrasts with analysis of trends in drinking by age that suggest that adults drink more frequently as they get older, though overall consumption declines with age. ${ }^{2}{ }^{3}$ These results extend the findings of previous analysis through considering the relationship between changes in health and drinking frequency. Our findings support the suggestion that frequent drinking in later life signifies good health, measured by SRH and depressive symptoms. ${ }^{17}$ For depression, existing research demonstrates that depression is a risk factor for heavy drinking. ${ }^{16} 31$ The results of this analysis demonstrate that having symptoms of depression is associated with less frequent drinking. This suggests that some older people with depression may self-medicate with alcohol and consume more, while others may reduce how often they drink, especially given adverse interactions with medication.

However, it should be noted that the analysis of the longitudinal cohort data cannot fully account for attrition from ELSA between each wave. Attrition between waves 0 and 4/5 was higher among non-drinkers rather than drinkers. This has

Table 3 Cross-tabulation of frequency of drinking at wave 0 by transitions in depressive symptoms between waves 0 and 5

\begin{tabular}{|c|c|c|c|c|}
\hline \multirow[b]{3}{*}{ Frequency of drinking wave 0} & \multicolumn{4}{|c|}{ Depressive symptoms: transitions between waves 0 and 5} \\
\hline & \multicolumn{2}{|c|}{ No depressive symptoms wave 0} & \multicolumn{2}{|c|}{ Depressive symptoms wave 0} \\
\hline & $\begin{array}{l}\text { Continual no depression } \\
\mathrm{n}=3328 \\
\text { Per cent }\end{array}$ & $\begin{array}{l}\text { Becomes depressed } n=279 \\
\text { Per cent }\end{array}$ & $\begin{array}{l}\text { Depression remains } \\
n=473 \\
\text { Per cent }\end{array}$ & $\begin{array}{l}\text { Depression improves } \mathrm{n}=386 \\
\text { Per cent }\end{array}$ \\
\hline Does not drink & 7.4 & 10.8 & 14.3 & 10.6 \\
\hline Once/twice a year & 6.0 & 7.8 & 12.9 & 11.4 \\
\hline Once every couple of months & 4.9 & 8.0 & 7.2 & 9.3 \\
\hline $1-2$ times a month & 11.3 & 12.7 & 13.3 & 13.2 \\
\hline 1-2 days a week & 25.9 & 24.7 & 19.4 & 23.3 \\
\hline 3-4 days a week & 15.6 & 13.5 & 12.9 & 13.2 \\
\hline 5-6 days a week & 5.9 & 3.0 & 2.5 & 2.3 \\
\hline Almost every day & 23.1 & 19.4 & 17.6 & 16.6 \\
\hline
\end{tabular}


Table 4 Ordered logit model of drinking frequency of ELSA participants in waves 0,4 and 5 controlling for transitions in self-rated health: $\mathrm{N}=4741$

\begin{tabular}{|c|c|c|c|c|c|c|c|}
\hline \multirow[b]{2}{*}{ Variable } & \multicolumn{2}{|l|}{ Model 1a } & \multicolumn{2}{|l|}{ Model 1b } & \multirow[b]{2}{*}{ Variable } & \multicolumn{2}{|l|}{ Model 1b } \\
\hline & Coefficient & $p$ Value & Coefficient & p Value & & Coefficient & p Value \\
\hline \multicolumn{5}{|l|}{ Transitions in self-rated health $\times$ wave } & \multicolumn{3}{|l|}{ Marital status wave 0} \\
\hline Wave 0 & & & & & Married & 0.00 & \\
\hline Continual good health & 0.00 & & 0.00 & & Single & -0.28 & 0.25 \\
\hline Health deteriorates & -0.48 & 0.01 & -0.11 & 0.52 & Separated/divorced & 0.13 & 0.45 \\
\hline Continual poor health & -1.63 & $<0.01$ & -0.99 & $<0.01$ & Widowed & 0.04 & 0.80 \\
\hline Health improves & -1.27 & $<0.01$ & -0.93 & $<0.01$ & Employment wave 0 & & \\
\hline \multicolumn{5}{|l|}{ Wave 4} & Employed & 0.00 & \\
\hline Continual good health & 0.00 & & 0.00 & & Economically inactive & $<0.01$ & 0.99 \\
\hline Health deteriorates & -1.09 & $<0.01$ & -0.81 & $<0.01$ & Retired & 0.12 & 0.43 \\
\hline Continual poor health & -2.29 & $<0.01$ & -1.81 & $<0.01$ & \multicolumn{3}{|l|}{ Wealth wave 1} \\
\hline Health improves & -1.47 & $<0.01$ & -1.20 & $<0.01$ & Bottom quintile & 0.00 & \\
\hline \multicolumn{5}{|l|}{ Wave 5} & Second quintile & 0.73 & $<0.01$ \\
\hline Continual good health & 0.00 & & 0.00 & & Third quintile & 1.00 & $<0.01$ \\
\hline Health deteriorates & -1.09 & $<0.01$ & -0.81 & $<0.01$ & Fourth quintile & 1.61 & $<0.01$ \\
\hline Continual poor health & -2.41 & $<0.01$ & -1.99 & $<0.01$ & Top quintile & 2.34 & $<0.01$ \\
\hline Health improves & -1.55 & $<0.01$ & -1.31 & $<0.01$ & \multicolumn{3}{|l|}{ Education wave 0} \\
\hline \multicolumn{5}{|l|}{ Continual good health } & No education & 0.00 & \\
\hline Wave 0 & 0.00 & & 0.00 & & Compulsory education & 0.63 & $<0.01$ \\
\hline Wave 4 & -0.81 & $<0.01$ & -0.90 & $<0.01$ & Postcompulsory Education & 0.80 & $<0.01$ \\
\hline Wave 5 & -0.90 & $<0.01$ & -1.00 & $<0.01$ & Degree or higher & 1.75 & $<0.01$ \\
\hline \multicolumn{5}{|c|}{ Health deteriorates between waves 0 and 5} & \multicolumn{3}{|l|}{ Smoking wave 0} \\
\hline Wave 0 & 0.00 & & 0.00 & & Non-smoker & 0.00 & \\
\hline Wave 4 & -1.41 & $<0.01$ & -1.60 & $<0.01$ & Former occasional smoker & 0.38 & 0.08 \\
\hline Wave 5 & -1.65 & $<0.01$ & -1.89 & $<0.01$ & Former regular smoker & 1.27 & $<0.01$ \\
\hline \multicolumn{5}{|l|}{ Continual poor health } & Current smoker & 0.81 & $<0.01$ \\
\hline Wave 0 & 0.00 & & 0.00 & & \multicolumn{3}{|l|}{ BMI wave 0} \\
\hline Wave 4 & -1.47 & $<0.01$ & -1.72 & $<0.01$ & $25-30$ & 0.00 & \\
\hline Wave 5 & -1.68 & $<0.01$ & -1.99 & $<0.01$ & $<20$ & -0.62 & 0.11 \\
\hline \multicolumn{5}{|c|}{ Health improves between waves 0 and 5} & $20-25$ & 0.28 & 0.03 \\
\hline Wave 0 & 0.00 & & 0.00 & & $>30$ & -0.51 & $<0.01$ \\
\hline Wave 4 & -1.02 & $<0.01$ & -1.16 & $<0.01$ & & & \\
\hline Wave 5 & -1.18 & $<0.01$ & -1.37 & $<0.01$ & & & \\
\hline \multicolumn{8}{|l|}{$\begin{array}{l}\text { Gender ref: } \\
\text { Male }\end{array}$} \\
\hline Female & -1.54 & $<0.01$ & -1.18 & $<0.01$ & & & \\
\hline Age at wave 0 (confounding variable) & -0.04 & $<0.01$ & -0.03 & $<0.01$ & & & \\
\hline Likelihood ratio test* & & $<0.01$ & & $<0.01$ & & & \\
\hline
\end{tabular}

Model 1a includes SRH×wave, age wave 0 and gender.

Model $1 \mathrm{~b}$ includes SRH xwave, age wave 0 , gender, marital status, employment, net household wealth, education, smoking and BMI.

*The likelihood ratio test compares the meologit model with an ologit model, that is, if the mixed-effects ordered logit regression model is favoured over a standard ordered logit regression model.

BMI, body mass index; ELSA, English Longitudinal Study of Ageing; SRH, self-rated health.

implications for the analysis of the relationship between health and drinking frequency, if those present in wave 5 exhibited a different relationship between health and drinking, compared with older adults who were not present in all waves. The analysis is also restricted to health outcomes for which there are sufficient data to carry out the longitudinal analysis. For this reason, the analysis is restricted to more generalised health status (SRH) and depressive symptoms which has a high occurrence among ELSA participants $(25 \%$ of the sample was at risk of depression in at least one wave).

In summary, the analysis shows that older people with continual good SRH and mental health drink more often and their frequency of drinking is more consistent over time. Thus, disentangling a causal relationship between drinking and health is more complex than simply distinguishing between life-long abstainers and former drinkers. We concur with others that there is insufficient evidence to endorse the recommendation that drinking is beneficial for health. ${ }^{17}$ There are other confounding factors that impact on drinking in later life and health, and it is not possible to infer about possible health benefits in isolation of other individual characteristics and behaviours. In particular, more affluent older adults drink more and this group also enjoys better health, ${ }^{38}$ and analysis of the potential health benefits of drinking needs to carefully control for this association.

Though the analysis cannot confirm a causal relationship between health and frequency of drinking, on balance we conclude that the evidence suggests that we have to take seriously the suggestion that frequent drinking in later life is a signifier of good health. However, while the importance of the sick quitter 
Table 5 Ordered logit models of drinking frequency of ELSA participants in waves 0, 4 and 5 controlling for transitions in depressive symptoms: $\mathrm{N}=4741$

\begin{tabular}{|c|c|c|c|c|c|c|c|}
\hline \multirow[b]{2}{*}{ Variable } & \multicolumn{2}{|l|}{ Model 2a } & \multicolumn{2}{|l|}{ Model 2b } & \multirow[b]{2}{*}{ Variable } & \multicolumn{2}{|l|}{ Model 2b } \\
\hline & Coefficient & p Value & Coefficient & $\mathrm{p}$ Value & & Coefficient & p Value \\
\hline \multicolumn{5}{|l|}{ Transitions in depressive symptoms xwave } & \multicolumn{3}{|l|}{ Marital status wave 0} \\
\hline Wave 0 & & & & & Married & 0.00 & \\
\hline No depression & 0.00 & & 0.00 & & Single & -0.27 & 0.26 \\
\hline Becomes at risk of depression & -0.52 & 0.01 & -0.08 & 0.67 & Separated/divorced & 0.10 & 0.54 \\
\hline Continual depression & -1.04 & $<0.01$ & -0.14 & 0.56 & Widowed & 0.08 & 0.62 \\
\hline Depression improves & -0.98 & $<0.01$ & -0.34 & 0.09 & Employment wave 0 & & \\
\hline \multicolumn{5}{|l|}{ Wave 4} & Employed & 0.00 & \\
\hline No depression & 0.00 & & 0.00 & & Economically inactive & -0.31 & 0.05 \\
\hline Becomes at risk of depression & -1.18 & $<0.01$ & -0.72 & $<0.01$ & Retired & -0.03 & 0.85 \\
\hline Continual depression & -2.20 & $<0.01$ & -1.27 & $<0.01$ & \multicolumn{3}{|l|}{ Wealth wave 1} \\
\hline Depression improves & -1.46 & $<0.01$ & -0.82 & $<0.01$ & Bottom quintile & 0.00 & \\
\hline \multicolumn{5}{|l|}{ Wave 5} & Second quintile & 0.73 & $<0.01$ \\
\hline No depression & 0.00 & & 0.00 & & Third quintile & 1.09 & $<0.01$ \\
\hline Becomes at risk of depression & -1.18 & $<0.01$ & -0.72 & $<0.01$ & Fourth quintile & 1.60 & $<0.01$ \\
\hline Continual depression & -1.94 & $<0.01$ & -1.02 & $<0.01$ & Top quintile & 2.47 & $<0.01$ \\
\hline Depression improves & -1.24 & $<0.01$ & -0.60 & 0.02 & \multicolumn{3}{|l|}{ Education wave 0} \\
\hline \multicolumn{5}{|l|}{ No depression } & No education & \multicolumn{2}{|l|}{0.00} \\
\hline Wave 0 & 0.00 & & 0.00 & & Compulsory education & 0.68 & $<0.01$ \\
\hline Wave 4 & -0.96 & $<0.01$ & -0.95 & $<0.01$ & Postcompulsory education & 0.87 & $<0.01$ \\
\hline Wave 5 & -1.14 & $<0.01$ & -1.13 & $<0.01$ & Degree or higher & 1.86 & $<0.01$ \\
\hline \multicolumn{5}{|c|}{ Becomes at risk of depression between waves 0 and 5} & \multicolumn{3}{|l|}{ Smoking wave 0} \\
\hline Wave 0 & 0.00 & & 0.00 & & Non-smoker & 0.00 & \\
\hline Wave 4 & -1.61 & $<0.01$ & -1.59 & $<0.01$ & Used to smoke occasionally & 0.35 & $<0.01$ \\
\hline Wave 5 & -1.73 & $<0.01$ & -1.71 & $<0.01$ & Used to smoke regularly & 1.20 & $<0.01$ \\
\hline \multicolumn{5}{|l|}{ Continual depression } & Current smoker & 0.67 & $<0.01$ \\
\hline Wave 0 & 0.00 & & 0.00 & & \multicolumn{3}{|l|}{ BMI wave 0} \\
\hline Wave 4 & -2.12 & $<0.01$ & -2.08 & $<0.01$ & $25-30$ & 0.00 & \\
\hline Wave 5 & -2.04 & $<0.01$ & -2.01 & $<0.01$ & $<20$ & -0.60 & 0.13 \\
\hline \multicolumn{5}{|c|}{ Depression improves between waves 0 and 5} & $20-25$ & 0.34 & 0.01 \\
\hline Wave 0 & 0.00 & & 0.00 & & $>30$ & -0.61 & $<0.01$ \\
\hline Wave 4 & -1.43 & $<0.01$ & -1.42 & $<0.01$ & & & \\
\hline Wave 5 & -1.39 & $<0.01$ & -1.39 & $<0.01$ & & & \\
\hline \multicolumn{8}{|l|}{ Gender } \\
\hline Ref: male & 0.00 & & 0.00 & & & & \\
\hline Female & -1.55 & $<0.01$ & -1.18 & $<0.01$ & & & \\
\hline Age at wave 0 (confounding variable) & -0.04 & $<0.01$ & -0.03 & & & & \\
\hline Likelihood ratio test* & & $<0.01$ & & $<0.01$ & & & \\
\hline
\end{tabular}

Model $2 \mathrm{a}$ includes depressive symptoms $\times$ wave, age wave 0 and gender.

Model $2 \mathrm{~b}$ includes depressive symptoms $\times$ wave, age wave 0 , gender, marital status, employment, net household wealth, education, smoking and BMI.

*The likelihood ratio test compares the meologit model with an ologit model, that is, if the mixed-effects ordered logit regression model is favoured over a standard ordered logit regression model.

BMI, body mass index; ELSA, English Longitudinal Study of Ageing.

effect is well established, relatively little is known about the mechanisms through which health status may moderate drinking behaviours. Further research could explore why older people

\section{What is already known on this subject}

Consumption of alcohol among older people in England has remained stable in recent years in contrast to declining consumption among younger age groups. Alcohol-related mortality and morbidity is also increasing among the individuals over 55 years. The putative relationship between good health and moderate alcohol consumption is increasingly being contested. drink less as their health declines, including the role of medical advice, possible interactions with medication and fewer opportunities to socialise due to deteriorating health. 
Contributors $\mathrm{CH}$ and NS conceived the study. MM created the data set from different ESLA waves and derived new variables. $\mathrm{CH}$ and MM completed analyses with advice from HP and $\mathrm{CdO}$. CH wrote the paper and MF, MM, CdO, HP and NS contributed to revisions of the paper.

Funding Economic and Social Research Council. Award Number: ES/K004131/1 Competing interests None declared.

Ethics approval Ethical approval for all the ELSA waves was granted by the Multi-centre Research and Ethics Committee (MREC).

Provenance and peer review Not commissioned; externally peer reviewed.

Data sharing statement Access to ELSA data can be made through the UK Data Service at: http://www.ukdataservice.ac.uk

Open Access This is an Open Access article distributed in accordance with the terms of the Creative Commons Attribution (CC BY 4.0) license, which permits others to distribute, remix, adapt and build upon this work, for commercial use, provided the original work is properly cited. See: http://creativecommons.org/ licenses/by/4.0/

\section{REFERENCES}

1 Meng Y, Holmes J, Hill-McManus D, et al. Trend analysis and modelling of gender-specific age, period and birth cohort effects on alcohol abstention and consumption level for drinkers in Great Britain using the General Lifestyle Survey 1984-2009. Addiction 2014;109:206-15.

2 Meier P. Polarized drinking patterns and alcohol deregulation. Trends in alcohol consumption, harms and policy: United Kingdom 1990-2010. Nord Stud Alcohol Drugs 2010;27:383-408.

3 Office National Statistics. Alcohol-related deaths rose in the 1990s and 2000s before stabilising in recent years. http://www.ons.gov.uk/ons/rel/subnational-health4/ alcohol-related-deaths-in-the-united-kingdom/2011/index.html (accessed Oct 2015).

4 Institute of Alcohol Studies. Alcohol consumption factsheet. London: Institute of Alcohol Studies, 2013. http://www.ias.org.uk/uploads/pdf/Consumption\%20docs/ Alcohol\%20consumption\%20factsheet\%20August\%202013.pdf (accessed Oct 2015).

5 Knott CS, Coombs N, Stamatakis E, et al. All cause mortality and the case for age specific alcohol consumption guidelines: pooled analyses of up to 10 population based cohorts. BMJ 2015;350:h384.

6 Lang I, Wallace RB, Huppert FA, et al. Moderate alcohol consumption in older adults is associated with better cognition and well-being than abstinence. Age Ageing 2007;36:256-61.

7 Anttila T, Helkala EL, Viitanen M, et al. Alcohol drinking in middle age and subsequent risk of mild cognitive impairment and dementia in old age: a prospective population based study. BMJ 2004;329:539.

8 Zanjani F, Downer BG, Kruger TM, et al. Alcohol effects on cognitive change in middle-aged and older adults. Aging Ment Health 2013;17:12-23.

9 Chen LY, Hardy CL. Alcohol consumption and health status in older adults: a longitudinal analysis. J Aging Health 2009;21:824-47.

10 Lin JC, Guerrieri JG, Moore AA. Drinking patterns and the development of functional limitations in older adults: longitudinal analyses of the health and retirement survey. J Aging Health 2011;23:806-21.

11 Moos RH, Schutte KK, Brennan PL, et al. Late-life and life history predictors of older adults' high-risk alcohol consumption and drinking problems. Drug Alcohol Depend 2010;108:13-20.

12 McCaul KA, Almeida OP, Hankey GJ, et al. Alcohol use and mortality in older men and women. Addiction 2010:105:1391-400.

13 Brennan PL, SooHoo S. Pain use of alcohol in later life: prospective evidence from the health and retirement study. J Aging Health 2013;25:656-77.

14 Holahan CJ, Schutte KK, Brennan PL, et al. Episodic heavy drinking and 20-year total mortality among late- life moderate drinkers. Alcohol Clin Exp Res 2014;38:1432-8.
15 Immonen S, Valvanne J, Pitkala KH. Prevalence of at-risk drinking among older adults and associated sociodemographic and health-related factors. J Nutr Health Aging 2011;15:789-94.

16 Choi NG, DiNitto DM. Heavy/binge drinking and depressive symptoms in older adults: gender differences. Int J Geriatr Psychiatry 2011;26:860-8.

17 Stockwell T, Room R. Constructing and responding to low-risk drinking guidelines: conceptualisation, evidence and reception. Drug Alcohol Rev 2012;31:121-5.

18 Hogenkamp PS, Benedict C, Sjogren P, et al. Late-life alcohol consumption and cognitive function in elderly men. Age (Dordr) 2014;36:243-9.

19 Holahan CJ, Schutte KK, Brennan PL, et al. Wine consumption and 20-year mortality among late-life moderate drinkers. I Stud Alcohol Drugs 2012:73:80-8.

20 Naimi T. Commentary on McCaul et al. (2010): Observational studies about average alcohol consumption and health-closing time for a limited evidence base. Addiction 2010;105:1401-2.

21 Shaper AG, Wannamethee G, Walker M. Alcohol and mortality in British men: explaining the U-shaped curve. Lancet 1988;332:1267-73.

22 Ronksley PE, Brien SE, Turner BJ, et al. Association of alcohol consumption with selected cardiovascular disease outcomes: a systematic review and meta-analysis. BMJ 2011;342:d671.

23 Rimm EB, Moats C. Alcohol and coronary heart disease: drinking patterns and mediators of effect. Ann Epidemiol 2007:17:S3-7.

$24 \mathrm{Ng}$ Fat L, Cable N, Marmot MG, et al. Persistent long-standing illness and non-drinking over time, implications for the use of lifetime abstainers as a control group. J Epidemiol Community Health 2014;68:71-7.

25 Stahre M, Roeber J, Kanny D, et al. Contribution of excessive alcohol consumption to deaths and years of potential life lost in the United States. Prev Chronic Dis 2014;11:E109.

26 Office National Statistics. Adult drinking habits in Great Britain, 2013. http://www. ons.gov.uk/ons/taxonomy/index.html?nscl=Alcohol+Consumption\#tab-data-tables (accessed Sep 2015).

27 Dawson DA, Goldstein RB, Grant BF. Prospective correlates of drinking cessation: variation across the life-course. Addiction 2013;108:712-22.

28 Jylha M. What is self-rated health and why does it predict mortality? Towards a unified conceptual model. Soc Sci Med 2009;69:307-16.

29 Balsa Al, Homer JF, Fleming MF, et al. Alcohol consumption and health among elders. Gerontologist 2008;48:622-36.

30 Platt A, Sloan FA, Costanzo P. Alcohol-consumption trajectories and associated characteristics among adults older than age 50. I Stud Alcohol Drugs 2010;71:169-79

31 Sacco P, Bucholz KK, Harrington D. Gender differences in stressful life events, social support, perceived stress, and alcohol use among older adults: results from a national survey. Subst Use Misuse 2014;49:456-65.

32 Steptoe A, Breeze E, Banks J, et al. Cohort profile: the English Longitudinal Study of Ageing. Int J Epidemiol 2013;42:1640-8.

33 Steffick DE. Documentation of affective functioning measures in the Health and Retirement Study. HRS/AHEAD Documentation Report 2000; DR-005. http:// hrsonline.isr.umich.edu/sitedocs/userg/dr-005.pdf (accessed Oct 2015).

34 Nazroo J, Zaninotto P, Gjonça E. Mortality and healthy life expectancy. In: Banks J, Breeze E, Lessof C, Nazroo J, eds. Living in the 21st century: older people in England the 2006 English Longitudinal Study Of Ageing (wave 3). London: Institute of Fiscal Studies, 2008:253-80.

35 Bobo JK, Greek AA, Klepinger DH, et al. Predicting 10-year alcohol use trajectories among men age 50 years and older. Am J Geriatr Psychiatry 2013;21:204-13.

36 Brennan PL, Schutte KK, Moos RH. Patterns and predictors of late-life drinking trajectories: a 10-year longitudinal study. Psychol Addict Behav 2010;24:254-64.

37 Britton A, Bell S. Reasons why people change their alcohol consumption in later life: findings from the Whitehall II cohort study. PLOS ONE 2015;10:e0119421.

38 Grundy E, Sloggett A. Health inequalities in the older population: the role of personal capital, social resources and socio-economic circumstances. Soc Sci Med 2003;56:935-47. 